\title{
Development of Causal Interactions Between Systolic Blood Pressure and Inter-Beat Intervals in Adolescents
}

\author{
J. SVAČINOVÁ ${ }^{1}$, M. JAVORKA ${ }^{2}$, Z. NOVÁKOVÁ ${ }^{1,3}$, E. ZÁVODNÁ ${ }^{3}$, B. CZIPPELOVÁ ${ }^{2}$ \\ N. HONZÍKOVÁ ${ }^{3}$
}

${ }^{1}$ Department of Physiology, Faculty of Medicine, Masaryk University, Brno, Czech Republic, ${ }^{2}$ Department of Physiology and Biomedical Center "BioMed Martin", Jessenius Faculty of Medicine, Comenius University, Martin, Slovak Republic, ${ }^{3}$ International Clinical Research Center, St. Anne's University Hospital Brno, Brno, Czech Republic

Received April 1, 2015

Accepted June 5, 2015

On-line October 8, 2015

\section{Summary}

Systolic blood pressure (SBP) changes control the cardiac interbeat intervals (IBI) duration via baroreflex. Conversely, SBP is influenced by IBI via non-baroreflex mechanisms. Both causal pathways (feedback - baroreflex and feedforward - nonbaroreflex) form a closed loop of the SBP - IBI interaction. The aim of this study was to assess the age-related changes in the IBI - SBP interaction. We have non-invasively recorded resting beat-to-beat SBP and IBI in 335 healthy subjects of different age, ranging from 11 to 23 years. Using a linear autoregressive bivariate model we obtained gain (Gain ${ }_{\mathrm{SBP}, \mathrm{IBI}}$, used traditionally as baroreflex sensitivity) and coherence ( $\mathrm{Coh}_{\mathrm{SBP}, \mathrm{IBI}}$ ) of the SBP-IBI interaction and causal gain and coherence in baroreflex (Gain $_{\mathrm{SBP} \rightarrow \mathrm{IBI}}$, Coh $\mathrm{SBP} \rightarrow \mathrm{IBI}$ ) and coherence in non-baroreflex $\left(\right.$ Coh $\left._{\text {IBI } \rightarrow \text { SBP }}\right)$ directions separately. A non-linear approach was used for causal coupling indices evaluation ( $\mathrm{C}_{\mathrm{SBP} \rightarrow \mathrm{IBI}}, \mathrm{C}_{\mathrm{IBI} \rightarrow \mathrm{SBP}}$ ) quantifying the amount of information transferred between signals. We performed a correlation to age analysis of all measures. $\mathrm{Coh}_{\mathrm{IBI} \rightarrow \mathrm{SBP}}$ and $\mathrm{C}_{\mathrm{IBI} \rightarrow \mathrm{SBP}}$ were higher than $\mathrm{Coh}_{\mathrm{SBP} \rightarrow \mathrm{IBI}}$ and $\mathrm{C}_{\mathrm{SBP} \rightarrow \mathrm{IBI}}$ respectively. Gain $\mathrm{SBP}, \mathrm{IBI}$ increased and $\mathrm{Coh}_{\mathrm{SBP} \rightarrow \mathrm{IBI}}$ decreased with age. The coupling indices did not correlate with age. We conclude that the feedforward influence dominated at rest. The increase of Gain $_{S B P, I B I}$ with age was not found in the closed loop model. A decrease of $\mathrm{Coh}_{\mathrm{SBP} \rightarrow \text { IBI }}$ could be related to a change in the cardiovascular control system complexity during maturation.

\section{Key words}

Baroreflex • Causality • Conditional entropy • Autonomic nervous system $\bullet$ Adolescents

\section{Corresponding author}

N. Honzíková, International Clinical Research Center, St. Anne's University Hospital Brno, Pekařská 53, 65691 Brno, Czech Republic. E-mail: natasa.honzikova@gmail.com

\section{Introduction}

Baroreflex is a basic nervous control cardiovascular mechanism. It is important in both the mean blood pressure control and the dampening of arterial blood pressure fluctuations acting mainly through the changes of the heart rate and vascular tone, and by the control of the cardiac contractility and of the capacitance vessels tone (Cowley et al. 1973, Eckberg 2000, Honzikova 2001, Honzikova and Fiser 2009).

The magnitude of heart rate changes in relation to blood pressure changes traditionally considered to be mediated by the stimulation of baroreceptors is expressed as baroreflex sensitivity (BRS). BRS is usually defined as the change of the pulse interval or inter-beat interval (IBI; a reciprocal value of the heart rate) associated with a change of systolic blood pressure (SBP) by $1 \mathrm{~mm} \mathrm{Hg}$ (Bristow et al. 1969). BRS is regarded as an important diagnostic and prognostic marker related to cardiovascular control in pathological conditions, 
particularly after myocardial infarction, in hypertensive or diabetic patients, and in obese people (Honzikova et al. 2000a, Krontoradova et al. 2008, Lazarova et al. 2009, Svacinova et al. 2013).

BRS can be evaluated from the spontaneous variability of IBI and SBP in the frequency domain as a transfer function gain, where oscillations in SBP and IBI are regarded as input and output signals, respectively (Honzikova et al. 1992). However, spectral assessment of BRS is hampered by non-baroreflex mediated heart rate variability, which adds to the baroreflex mediated heart rate variability (Frederics et al. 1997). Moreover, the presumed unidirectional relationship (open loop model) is now considered to be too simplified, because heart rate changes could also evoke changes in SBP (Porta et al. 2002). This phenomenon - non-baroreflex feedforward influence - results from the effect of the heart rate on diastolic heart filling affecting systolic contraction via the Frank-Starling mechanism and from the effect of the IBI duration on the magnitude of the blood pressure decrease during the diastolic phase of the cardiac cycle (run-off phenomenon). Additionally, blood pressure itself is a target of the baroreflex effect on the heart rate. Therefore, a causal closed loop model with a separate analysis of both feedback (baroreflex influence; in the direction from SBP to IBI) and feedforward (nonbaroreflex influence; in the direction from IBI to SBP) influences should be preferred (Porta et al. 2002).

Causal bidirectional interaction between SBP and IBI signals can be analyzed by a linear or non-linear approach. Using the linear approach, the bivariate autoregressive model allows the estimation of unidirectional causal coherences (representing the strength of the linear coupling in the given direction) and gains (representing the ratio of the output and input signal amplitude) separately in both non-baroreflex and baroreflex directions (Porta et al. 2002, Faes et al. 2004). Alternatively the non-linear - model-free information domain approach is based on a conditional entropy calculation and it enables the quantification of causal coupling indices. Coupling indices determine the amount of information transferred between signals in both feedback (baroreflex) and feedforward (non-baroreflex) directions (Faes et al. 2013).

Our study was focused on the assessment of the baroreflex function development in the age range of 11-23 years using the causal approach. The aim of this study was to assess the changes in feedback and feedforward interactions between SBP and IBI signals using a linear and non-linear causal approach and to compare its performance to the classical open loop baroreflex function analysis.

\section{Methods}

\section{Subjects}

We examined 335 volunteers (171 males/ 164 females) between 11-23 years of age. The participants were recruited from eight schools in the city of Brno (Czech Republic). The examined subjects represent a general city population in the Czech Republic uninfluenced by any selection, e.g. with respect to body mass index (BMI) or physical activity level. Subjects (aged $>18$ years) and parents of subjects or legal representatives of subjects (subjects aged $<18$ years) were questioned about their personal and family histories. The subjects did not report any chronic diseases (particularly cardiovascular diseases, bronchial asthma or diabetes mellitus). According to the family history, one of the parents was treated for hypertension in $13 \%$ of the subjects, and both parents were treated for hypertension in $1 \%$ of the subjects. We have analyzed the age dependence of the assessed measures in the whole group of subjects and also separately in two age subgroups (11-16 years, $\mathrm{N}=171$ and $17-23$ years, $\mathrm{N}=164$ ). For a more detailed presentation of the data, the division into six subgroups was performed (11-12 years: $\mathrm{N}=37$, 11 males/26 females; $13-14$ years: $\mathrm{N}=82,51$ males/ 31 females; $15-16$ years: $\mathrm{N}=52,27$ males $/ 25$ females; 17-19 years: $\mathrm{N}=65,29$ males/36 females; $19-20$ years: $\mathrm{N}=32,14$ males $/ 18$ females, and $21-23$ years: $\mathrm{N}=67$, 39 males $/ 28$ females).

The Ethics Committee of Masaryk University in Brno approved the study, and adult participants or the parents of each child gave their written informed consent.

\section{Study protocol}

We non-invasively and continuously recorded finger arterial blood pressure during $5 \mathrm{~min}$ in the sitting position using the volume clamp method (Finapres 2300, Ohmeda, USA). The finger cuff was placed on the middle phalanx of the $3^{\text {rd }}$ or $4^{\text {th }}$ finger and the hand was fixed at the level of the participant's heart. The examinations were performed in a quiet room with the temperature controlled at $22{ }^{\circ} \mathrm{C}$ during morning hours (9-12 a.m.). The subjects rested for 15 min after the placing of a Finapres cuff and were in a sitting position, allowing the cardiovascular system to reach a quasi-stationary 
steady state condition. The breathing rate $(0.33 \mathrm{~Hz}$, 20 breaths per minute) was self-controlled by probands following the metronome. The subjects were allowed to adjust the tidal volume according to their own needs.

\section{Data analysis}

After the detection of systolic blood pressure values (SBP; defined as the local maximum in the continuous blood pressure curve) and inter-beat intervals (IBI; defined as a time interval between two neighbouring systolic blood pressures) from the blood pressure signal, two 300 heart beats long time series, consisting of beatto-beat SBP and IBI values, were generated. SBP and IBI time series were aligned as follows: $i^{\text {th }}$ SBP value was located at the beginning of the $i^{\text {th }}$ IBI. Both signals were linearly detrended to avoid the effect of long-term trends in the signals on the data analysis.

\section{Linear analysis}

First, we assessed the interactions between the signals by using the linear - frequency domain approach. The method is based on a bivariate linear autoregressive model (Faes et al. 2004, Porta et al. 2002)

$$
\begin{aligned}
& i b i(t)=\sum_{k=1}^{p} a_{11}(k) i b i(t-k)+\sum_{k=0}^{p} a_{12}(k) \operatorname{sbp}(t-k)+w_{1}(t) \\
& \operatorname{sbp}(t)=\sum_{k=1}^{p} a_{21}(k) i b i(t-k)+\sum_{k=1}^{p} a_{22}(k) \operatorname{sbp}(t-k)+w_{2}(t)
\end{aligned}
$$

where $\operatorname{sbp}(t)$ and $i b i(t)$ represent beat-to-beat systolic blood pressure and inter-beat intervals time series, respectively, $w_{1}$ and $w_{2}$ are zero-mean white noises and $a_{11}, a_{12}, a_{21}$ and $\mathrm{a}_{22}$ are the estimated vectors of the regression coefficients. $p$ is the model order chosen based on the Akaike criterion for multivariate processes. After transforming these equations into the frequency domain, it is possible to estimate the transfer function between the analyzed signals including coherence and gain as the functions corresponding to the given frequency of oscillations.

As the first step we used the classical open loop model, first proposed by Robbe et al. (1987), where the unidirectional influence from SBP to IBI based on baroreflex (blood pressure change evokes a pulse interval change but not vice versa) is proposed. We calculated the gain $\left(\mathrm{Gain}_{\mathrm{SBP}, \mathrm{IBI}}[\mathrm{ms} / \mathrm{mm} \mathrm{Hg}]\right)$ in the low frequency band (LF: 0.04-0.15 Hz) usually regarded as an index of baroreflex sensitivity (BRS). Additionally, coherence in this band was calculated ( $\left.\mathrm{Coh}_{\mathrm{SBP}, \mathrm{IBI}}\right)$ as described previously (Honzíková et al. 1992, Závodná et al. 2006).

The causal analysis enables the separate assessment of the causal coherences $\left(\mathrm{Coh}_{\mathrm{SBP} \rightarrow \mathrm{IBI}}\right.$ and $\left.\mathrm{Coh}_{\mathrm{IBI} \rightarrow \mathrm{SBP}}\right)$ in both directions by separately switching off the feedback or the feedforward path by setting the appropriate coefficients to zero. Causal gains can similarly be determined. We calculated causal gain $\left(\mathrm{Gain}_{\mathrm{SBP} \rightarrow \mathrm{IBI}}[\mathrm{ms} / \mathrm{mm} \mathrm{Hg}]\right)$ with the aim of comparing this measure with baroreflex sensitivity determined as Gain $_{\mathrm{SBP}, \mathrm{IBI}}[\mathrm{ms} / \mathrm{mm} \mathrm{Hg}$ ] by the open loop model. We confined the analysis to a low frequency band (LF, $0.04-0.15 \mathrm{~Hz}$ ) to minimize the effect of other mechanisms on the baroreflex assessment. The values of causal coherences and gain were calculated as the arithmetic mean of their values within this band.

\section{Information domain analysis}

We have investigated the causality between inter-beat intervals and blood pressure signals in an information domain separately analyzing the coupling strength of the causal interactions from IBI to SBP and from SBP to IBI by the calculation of corrected conditional entropies employing a non-uniform conditioning approach (Faes et al. 2011, 2013). This method separately quantifies the causal coupling from the series IBI to the series $\mathrm{SBP}\left(\mathrm{C}_{\mathrm{IBI} \rightarrow \mathrm{SBP}}\right)$ and from the series SBP to the series IBI $\left(\mathrm{C}_{\mathrm{SBP} \rightarrow \mathrm{IBI}}\right)$ as the amount of information flowing from the former to the latter signal. In addition, the difference between two reciprocal causal couplings $\left(\mathrm{C}_{\mathrm{SBP} \rightarrow \mathrm{IBI}}-\mathrm{C}_{\mathrm{IBI} \rightarrow \mathrm{SBP}}\right)$ is taken as a measure of directionality $\left(\mathrm{D}_{\mathrm{SBP}, \mathrm{IBI}}\right)$ - its value is positive when the baroreflex feedback mechanism is a prevailing causal direction in the cardiovascular control loop. In contrast, directionality is negative, when the non-baroreflex feedforward connection dominates within the closed loop $s b p-i b i$ interaction.

\section{Statistics}

Due to the non-Gaussian distribution of assessed variables, non-parametric tests were used. The Wilcoxon test was used in each of six age groups for the evaluation of differences between the contribution of feedforward $(\mathrm{IBI} \rightarrow \mathrm{SBP})$ and feedback $\quad(\mathrm{SBP} \rightarrow \mathrm{IBI})$ directions. Spearman correlation coefficients $(r)$ were calculated to assess the age dependence of all analyzed variables within the whole sample and two subgroups (11-16 and 17-23 years). Squared coherences were used in the analysis. 


\section{Results}

\section{Open loop linear model}

Using age as a continuous variable, no significant correlation between age and the open loop model coherence $\left(\mathrm{Coh}^{2}{ }_{\text {SBP,IBI }}\right)$ was found (Table 1). After dividing the subjects into two age groups, a significant positive correlation of $\mathrm{Coh}_{\text {SBP,IBI }}^{2}$ to age was found in the younger age subgroup (11-16 years). In contrast, Gain $_{\text {SBP,IBI }}$ significantly increased with age in the whole sample (11-23 years). Similarly after the division of subjects into two age subgroups, a significant increase of Gain $_{\mathrm{SBP}, \mathrm{IBI}}$ with age persisted only in the age group of 11-16 years. Box plots of gains and coherences in six age groups are presented in Figures 1 and 2.

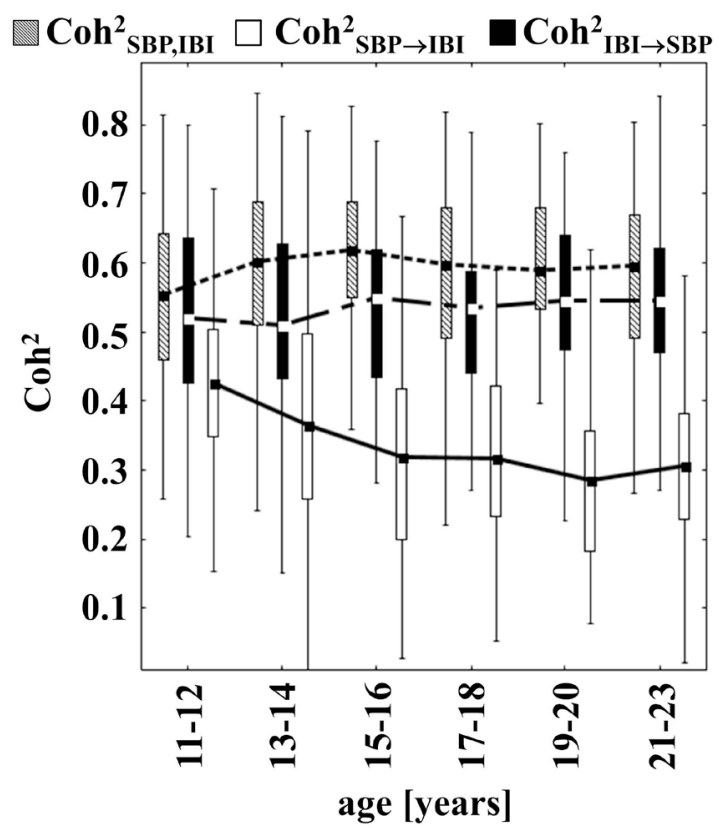

Fig. 1. Squared coherences derived from the bivariate linear autoregressive model. Open loop model: coherence ( $\left.\mathrm{Coh}^{2}{ }_{\mathrm{SBP}, \mathrm{IBI}}\right)$. Closed-loop model: causal feedforward coherence $\left(\mathrm{Coh}_{\text {IBI } \rightarrow \text { SBP }}\right.$ ) and causal feedback coherence $\left(\mathrm{Coh}_{\mathrm{SBP} \rightarrow \mathrm{IBI}}^{2}\right)$. The coherences of each subject were computed as a mean value in the low frequency band $(0.04-0.15 \mathrm{~Hz})$. IBI - inter-beat intervals, SBP systolic blood pressure. Distribution of each variable is described by boxplots (point: median, box: interquartile range, whiskers: range of non-outliers).

\section{Closed loop linear model - causal analysis}

By separately analyzing the strength of the feedback and feedforward interactions between IBI and SBP signals in the whole group, we found that feedback coherence from SBP to IBI significantly decreased with age but no significant effect of age on feedforward coherence was found (Table 1). When analyzing the two subgroups separately, a decrease of feedback coherence was only observed in the age group of 11-16 years. Throughout all age groups, the $\mathrm{Coh}^{2}{ }_{\mathrm{IBI} \rightarrow \mathrm{SBP}}$ was higher than $\mathrm{Coh}_{\mathrm{SBP} \rightarrow \mathrm{IBI}}$ (Wilcoxon test, $\mathrm{p}<0.01$ in each age group, Fig. 1). The causal gain in the baroreflex direction Gain $_{\mathrm{SBP} \rightarrow \mathrm{IBI}}$ did not change significantly with age.

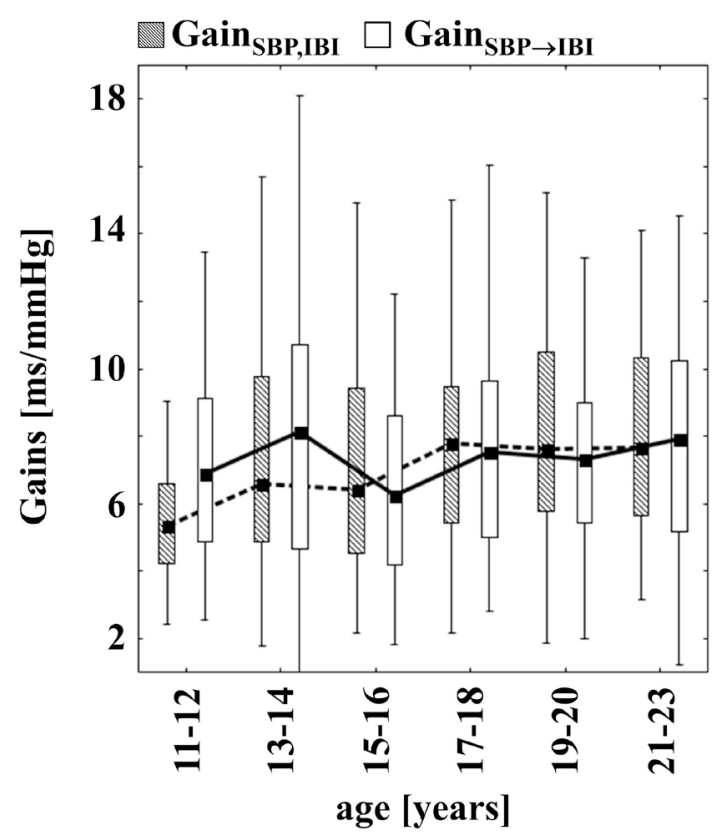

Fig. 2. Gains derived from the bivariate linear autoregressive model. Open loop model: gain (Gain $\left.{ }_{S B P, I B I}\right)$. Closed-loop model: causal feedback gain (Gain ${ }_{S B P} \rightarrow$ IBI $)$. The gains of each subject were computed as a mean value in the low frequency band (0.04-0.15 Hz). IBI - inter-beat intervals, SBP - systolic blood pressure. Distribution of each variable is described by boxplots (point: median, box: interquartile range, whiskers: range of nonoutliers).

\section{Information domain causality analysis}

Box plots of causal coupling indices in six age groups are presented in Figure 3. The causal coupling index $\mathrm{C}_{\mathrm{IBI} \rightarrow \mathrm{SBP}}$ quantifying the amount of information transferred in the non-baroreflex direction was significantly higher than the coupling index $\mathrm{C}_{\mathrm{SBP} \rightarrow \mathrm{IBI}}$ (Wilcoxon test, $\mathrm{p}<0.05$ in each age group except the age group 11-12 years with $\mathrm{p}=0.053$ ). While no significant correlation between age and $\mathrm{C}_{\mathrm{SBP} \rightarrow \mathrm{IBI}}$ was found, the $\mathrm{C}_{\mathrm{IBI} \rightarrow \mathrm{SBP}}$ tended to increase with age $(\mathrm{r}=0.101$, $\mathrm{p}=0.063)$. Though the directionality index $\mathrm{D}_{\mathrm{IBI}, \mathrm{SBP}}$ in individual subjects was positive or negative (Fig. 3), on average it was negative in each age group and did not correlate to age (Table 2). In addition, no correlations were found in any of the information domain measures when two subgroups (11-16 and 17-23 years) were analyzed separately. 


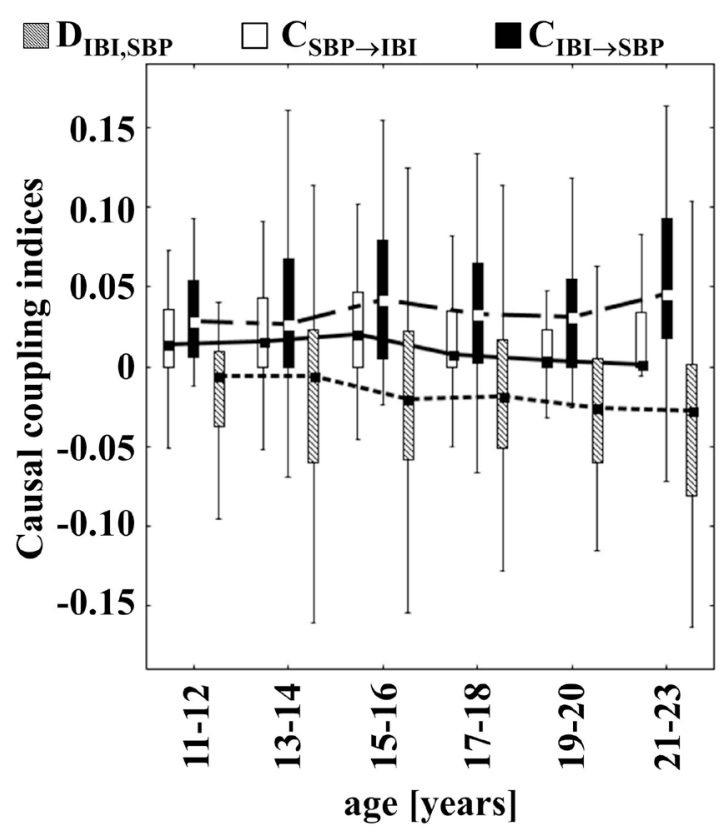

Fig. 3. Feedback causal coupling indices $\left(\mathrm{C}_{\mathrm{SBP} \rightarrow \mathrm{IBI}}\right)$, feedforward causal coupling index $\left(\mathrm{C}_{\mathrm{IBI} \rightarrow \mathrm{SBP}}\right)$ and directionality index $\left(\mathrm{D}_{\mathrm{IBI}, \mathrm{SBP}}\right)$ from the information domain analysis. The coupling indices express the amount of information flowing from the former to the latter signal (from SBP to IBI, or from IBI to SBP) and the directionality index is calculated as their difference. IBI - interbeat intervals, SBP - systolic blood pressure. Distribution of each variable is described by boxplots (point: median, box: interquartile range, whiskers: range of non-outliers).

Table 1. Spearman correlation coefficients of squared coherence and gain ( $\left.\mathrm{Coh}_{\mathrm{SBP}, \mathrm{IBI}} \mathrm{Gain}_{\mathrm{SBP}, \mathrm{IBI}}\right)$ of the open loop model, causal squared coherence and gain in the feedback baroreflex direction $\left(\mathrm{Coh}_{\mathrm{SBP} \rightarrow \mathrm{BBI}} \mathrm{COh}_{\mathrm{SBP} \rightarrow \mathrm{IBI}}\right.$ ) and causal squared coherence in the feedforward non-baroreflex direction ( $\left.\mathrm{Coh}_{\mathrm{IBI} \rightarrow \mathrm{SBP}}^{2}\right)$ with age.

\begin{tabular}{llllll}
\hline & $\mathbf{C o h}_{\text {SBP,IBI }}$ & $\mathbf{C o h}_{\text {IBI } \rightarrow \text { SBP }}$ & $\mathbf{C o h}_{\text {SBP } \rightarrow \text { IBI }}$ & Gain $_{\text {SBP,IBI }}$ & Gain $_{\text {SBP } \rightarrow \text { IBI }}$ \\
\hline 11-23 years $(N=335)$ & 0.029 & 0.029 & $-0.225^{* * *}$ & $0.228^{* * *}$ & 0.045 \\
$11-16$ years $(N=171)$ & $0.119 *$ & -0.041 & $-0.205^{* *}$ & $0.190^{*}$ & -0.064 \\
$17-23$ years $(N=164)$ & -0.014 & -0.072 & -0.033 & 0.084 & 0.096 \\
\hline
\end{tabular}

The correlations were calculated for the whole group of subjects (11-23 years) and for two subgroups (11-16 and 17-23 years) separately. IBI - inter-beat intervals, SBP - systolic blood pressure. * denotes significant correlation with $0.01 \leq p<0.05 ; * *$ denotes $0.0001 \leq \mathrm{p}<0.01 ; * * *$ denotes $\mathrm{p}<0.0001$.

Table 2. Spearman correlation coefficients of causal coupling indices $\mathrm{C}_{\mathrm{IBI} \rightarrow \mathrm{SBP}}$ in the non-baroreflex direction, $\mathrm{C}_{\mathrm{SBP} \rightarrow \mathrm{IBI}}$ in the baroreflex direction and the directionality index $\mathrm{D}_{\mathrm{IBI}, \mathrm{SBP}}$ with age.

\begin{tabular}{lccc}
\hline & $\begin{array}{c}\mathbf{1 1 - 2 3} \text { years } \\
\mathbf{( N = 3 3 5 )}\end{array}$ & $\begin{array}{c}\mathbf{1 1 - 1 6} \text { years } \\
\mathbf{( N = 1 7 1 )}\end{array}$ & $\begin{array}{c}\mathbf{1 7 - 2 3} \text { years } \\
\mathbf{( N = 1 6 4 )}\end{array}$ \\
\hline$C_{I B I \rightarrow S B P}$ & 0.101 & 0.084 & -0.036 \\
$C_{S B P \rightarrow I B I}$ & -0.058 & 0.115 & 0.122 \\
$D_{I B I, S B P}$ & -0.092 & 0.023 & -0.105 \\
\hline
\end{tabular}

The correlations were calculated for the whole group of subjects (11-23 years) and for two age subgroups (11-16 and 17-23 years). IBI - inter-beat intervals, SBP - systolic blood pressure.

\section{Discussion}

Two major findings are presented in this study. First, the coupling between IBI and SBP in the feedforward non-baroreflex direction (from IBI to SBP) is stronger than that in the feedback baroreflex direction (from SBP to IBI) in resting conditions, regardless of age. This finding was confirmed by both the causal coherence derived from the linear bivariate model and the coupling index derived from the information domain analysis. Second, the causal coherence quantifying the strength of the linear coupling from SBP to IBI decreased with age.

In our study, we have applied both the noncausal closed loop model and the causal closed loop model for the analysis of systolic blood pressure - interbeat intervals interactions and their age-dependent changes during late childhood, adolescence and early adulthood. The conventionally used open loop approach is based on the assumption that blood pressure oscillations evoke changes in inter-beat intervals via baroreflex. However, recent studies on small samples of subjects consistently showed that - in addition to the 
baroreflex feedback mechanism - a feedforward interaction characterized by an influence of the inter-beat intervals on the SBP values should not be neglected (Porta et al. 2002). Moreover, it was demonstrated that the feedforward influence dominates in the closed loop model of SBP - IBI interactions at rest in the supine position (Porta et al. 2002, 2011, Faes et al. 2013, Javorka et al. 2014). These studies also showed that the dominant direction switched from the feedforward $(\mathrm{IBI} \rightarrow \mathrm{SBP})$ to the feedback (baroreflex) direction $(\mathrm{SBP} \rightarrow \mathrm{IBI})$ during orthostatic challenge. Porta et al. (2011) reported that the dominance of the relation from IBI to SBP gradually decreased with the magnitude of the orthostatic challenge. Our results extend these findings in several ways: in our large sample of subjects, we demonstrated that the feedforward influence is dominating also in the sitting position. Additionally, this finding was consistently found throughout all of the age groups (from 11 to 23 years) in the large sample of subjects and using both linear and information domain approaches. These observations indicate the importance of the causal approach based on the closed loop model of IBI - SBP interactions.

Using the open loop model, our results demonstrated an increase of the transfer function gain in the low frequency band with age in the young subjects aged 11-23 years. After splitting the subjects into two age-subgroups, this positive correlation was present only in the subgroup of subjects aged 11-16 years. Relatively few studies on physiological BRS values in children and adolescents have been published. Although the mean values of BRS described were similar to those of young healthy adults, the inter-individual differences were considerable. For example, Dietrich et al. (2006) described values between 2.3 and $73 \mathrm{~ms} / \mathrm{mm} \mathrm{Hg}$ in preadolescents (aged between 10 and 13 years), we have found values between 3.9 and $24.1 \mathrm{~ms} / \mathrm{mm} \mathrm{Hg}\left(5^{\text {th }}\right.$ and $95^{\text {th }}$ percentiles of BRS values distribution) in the subjects between 11 and 20 years (Zavodna et al. 2006). The high inter-individual differences could be responsible for the relatively weak correlations observed in our study.

Concerning the age-dependent changes of BRS, its decrease with age in adults has been known since the study of Gribbin et al. (1971) and has been confirmed in many studies (e.g. Kardos et al. 2001). In contrast, only a few studies on BRS development in children and adolescents have been published (Lenard et al. 2004, Dietrich et al. 2006, Zavodna et al. 2006). Childhood and adolescence is a period of cardiovagal autonomic function maturation characterized by an increase of vagal activity reflected by a gradual decrease of the heart rate. However, the effect of cardiovagal maturation in this developmental period on BRS is inconsistent. In the majority of studies, no age dependent changes of BRS were described in a sitting or supine position (Zavodna et al. 2006, Dietrich et al. 2006). On the other hand, Lenard et al. (2004) described an increase of BRS values in children and adolescents (from 11 to 18 years). The differences in the results could be better understood if the relationship between BRS and the heart rate at this age was also taken into account, because BRS also decreases with the heart rate, which means, it increases with the prolongation of IBI in the particular age groups (Allen et al. 2000, Zavodna et al. 2006). Zavodna et al. (2006) quantified BRS as a maximal value of gain inside LF band 0.07-0.12 Hz. In this study, we calculated gains in the whole low frequency band disregarding the coherence of the given frequency. Thus, it cannot be excluded that gains at the frequencies where low coherence was detected could influence the results. The gain in the feedback SBP $\rightarrow$ IBI direction - baroreflex sensitivity calculated from the more appropriate closed loop model did not change in relation to age in our study. This indicates that the short-term baroreflex function is already well developed in children of 11 years of age and it is in agreement with the studies mentioned above (Lenard et al. 2004, Dietrich et al. 2006, Zavodna et al. 2006).

With the increase in age from childhood to early adulthood, the causal coherence from SBP to IBI decreased. We suggest that this decrease indicates an enhancement of the influence of other (excluding baroreflex) inputs to the cardiovascular control centre resulting in a mild decrease of the relative contribution of baroreflex to the low frequency heart rate oscillations. This concept is in accordance with other studies indicating a change in the cardiovascular control system complexity during the maturation process (Beckers et al. 2006, Cysarz et al. 2013).

Limiting factors in this study include possible variations in the level of maturation of children in the given age group. More information about the pubertal stage of the subjects (e.g. Tanner score) might provide a new insight into the effect of sexual maturation on the cardiovascular control changes associated with age. This study is also limited by the lack of inclusion of a respiratory signal in the analysis. Respiration is a latent confounder in SBP - IBI interactions (Porta et al. 2012). Both blood pressure and heart rate signals are influenced 
by respiration. When analyzing interactions between IBI and SBP without the inclusion of a respiratory signal, the strength of the interaction between cardiovascular signals could be overestimated due to the influence of a common oscillator - respiratory signal - on both assessed cardiovascular signals. This could give rise to falsely increased causal couplings in the SBP - IBI interaction (Faes et al. 2011). The controlled respiration tried to minimize the influence of inter-individual differences in the respiratory pattern on cardiovascular oscillations but the effect of respiration cannot be completely excluded in the model-free based (information domain) results of our study. In addition, when using a linear approach for causality assessment, we tried to avoid the confounding effect of respiration by confining our analysis solely to the LF band, where the influence of the respiratory signal from the controlled respiration is expected to be negligible. Despite a potentially different effect of respiration on model-free and linear model causality indices, our results using both approaches found a consistently higher coherence in the $\mathrm{IBI} \rightarrow \mathrm{SBP}$ direction compared to the feedback direction in concordance with previous studies where the respiratory signal was or was not included (Faes et al. 2004, Porta et al. 2011). Considering this limitation, the inclusion of a respiratory signal in the analysis seems to be useful as a future development of the study.

In this study, IBI intervals were assessed from the finger blood pressure signal. We have used the IBI signal for BRS determination since 1992 (Honzikova et al. 1992) with comparable results based on the measurement of R-R intervals from ECG (Persson et al. 2001, Honzikova et al. 2000b). However, R-R intervals are normally used. A comparison of both methodologies was carried out (DelPaso et al. 2010). Pulse transit time is negatively associated with SBP; therefore the variability of IBI is slightly increased in association with SBP oscillations. This fact leads to slightly higher BRS estimated from IBI than BRS estimated from R-R intervals, because the variability of IBI is slightly higher than the variability of R-R intervals (DelPaso et al. 2010). Taking into consideration that the difference between both of the BRS estimations in the above mentioned studies were small we assume that the correlations of causal variables with age as the primary outcome of our study were not significantly influenced by using IBI instead of an R-R intervals signal to assess the causal interactions between SBP and cardiac cycle duration oscillations.

We conclude that the causal analysis of the interaction of blood pressure - inter-beat intervals oscillations could provide a new insight regarding the maturation of baroreflex and non-baroreflex mechanisms in childhood and adolescence. The consistently found dominance of the non-baroreflex feedforward interaction (from IBI to SBP) points towards a preferential choice of the closed-loop model for baroreflex function assessment.

\section{Conflict of Interest}

There is no conflict of interest.

\section{Acknowledgements}

This study was supported by Masaryk university as part of the project KASBUNPAC (Kardiovaskulární systém od buňky k lůžku pacienta) number MUNI/A/1326/2014 with the support of the Specific University Research Grant, as provided by the Ministry of Education, Youth and Sports of the Czech Republic in the year 2015, and by the grant projects: European Regional Development Fund - Project FNUSA-ICRC (No. CZ.1.05/1.1.00/02.0123), ITMS project "BioMed Martin" no. 26220220187, APVV-0235-12 and VEGA 1/0059/13.

\section{References}

ALLEN MT, MATTHEWS KA, KENYON KL: The relationships of resting baroreflex sensitivity, heart rate variability and measures of impulse control in children and adolescents. Int J Psychophysiol 37: 185-194, 2000.

BECKERS F, VERHEYDEN B, AUBERT AE: Aging and nonlinear heart rate control in a healthy population. Am $J$ Physiol Heart Circ Physiol 290: H2560-H2570, 2006.

BRISTOW JD, GRIBBIN B, HONOUR A J, PICKERING TG, SLEIGHT P: Diminished baroreflex sensitivity in high blood pressure and ageing man. $J$ Physiol 202: 45P-46P, 1969.

COWLEY AW, LIARD JF, GUYTON AC: Role of baroreceptor reflex in daily control of arterial blood pressure and other variables in dogs. Circ Res 32: 564-576, 1973. 
CYSARZ D, LINHARD M, EDELHAUSER F, LANGLER A, VAN LEEUWEN P, HENZE G, SEIFERT G: Symbolic patterns of heart rate dynamics reflect cardiac autonomic changes during childhood and adolescence. Auton Neurosci 178: 37-43, 2013.

DEL PASO GAR, GONZALEZ MI, HERNANDEZ JA: Comparison of baroreceptor cardiac reflex sensitivity estimates from inter-systolic and ECG R-R intervals. Psychophysiology 47: 1102-1108, 2010.

DIETRICH A, RIESE H, VAN ROON AM, VAN ENGELEN K, ORMEL J, NEELEMAN J, ROSMALEN JGM: Spontaneous baroreflex sensitivity in (pre)adolescents. J Hypertens 24: 345-352, 2006.

ECKBERG DL: Physiological basis for human autonomic rhythms. Ann Med 32: 341-349, 2000.

FAES L, PORTA A, CUCINO R, CERUTTI S, ANTOLINI R, NOLLO G: Causal transfer function analysis to describe the closed loop interactions between cardiovascular and cardiorespiratory variability signals. Biol Cybern 90 : 390-399, 2004.

FAES L, NOLLO G, PORTA A: Information domain approach to the investigation of cardio-vascular, cardiopulmonary, and vasculo-pulmonary causal couplings. Front Physiol 2: 80, 2011.

FAES L, NOLLO G, PORTA A: Mechanisms of causal interaction between short-term RR interval and systolic arterial pressure oscillations during orthostatic challenge. J Appl Physiol 114: 1657-1667, 2013.

FREDERIKS J, SWENNE CA, TENVOORDE BJ, HONZIKOVA N, LEVERT JV, MAAN AC, SCHALIJ MJ, BRUSCHKE AVG: Non-baroreflex mediated heart rate variability causes overestimation of baroreflex sensitivity. Comp Cardiol 24: 199-202, 1997.

GRIBBIN B, PICKERING TG, SLEIGHT P, PETO R: Effect of age and high blood pressure on baroreflex sensitivity in man. Circ Res 29: 424-427, 1971.

HONZIKOVA N: Contribution of continuous non-invasive recording of finger arterial blood pressure to physiological research and application in medicine and psychology: A methodological review. Homeostasis 41: 7-19, 2001.

HONZIKOVA N, FISER B: Baroreflex sensitivity and essential hypertension in adolescents. Physiol Res 58: 605-612, 2009.

HONZIKOVA N, FISER B, HONZIK J: Non-invasive determination of baroreflex sensitivity in man by means of spectral-analysis. Physiol Res 41: 31-37, 1992.

HONZIKOVA N, SMERAD B, FISER B, LABROVA R: Baroreflex sensitivity determined by spectral method and heart rate variability, and two-years mortality in patients after myocardial infarction. Physiol Res 49: 643-650, 2000a.

HONZIKOVA N, FISER B, SEMRAD B: Critical value of baroreflex sensitivity determined by spectral analysis in risk stratification after myocardial infarction. PACE 23: 1965-1967, 2000b.

JAVORKA M, CZIPPELOVA B, CHLADEKOVA L, TURIANIKOVA Z, VISNOVCOVA Z, LAZAROVA Z, TONHAJZEROVA I: Cardiovascular control during orthostatic and mental stress: conditional entropy based analysis. ESGCO 2014: 8th Conference of the European Study Group on Cardiovascular Oscillations, 13-14, 2014.

KARDOS A, WATTERICH G, DE MENEZES R, CSANADY M, CASADEI B, RUDAS L: Determinants of spontaneous baroreflex sensitivity in a healthy working population. Hypertension 37: 911-916, 2001.

KRONTORADOVA K, HONZIKOVA N, FISER B, NOVAKOVA Z, ZAVODNA E, HRSTKOVA H, HONZIK P: Overweight and decreased baroreflex sensitivity as independent risk factors for hypertension in children, adolescents, and young adults. Physiol Res 57: 385-391, 2008.

LENARD Z, STUDINGER P, MERSICH B, KOCSIS L, KOLLAI M: Maturation of cardiovagal autonomic function from childhood to young adult age. Circulation 110: 2307-2312, 2004.

LAZAROVA Z, TONHAJZEROVA I, TRUNKVALTEROVA Z, BROZMANOVA A, HONZÍKOVÁ N, JAVORKA $\mathrm{K}$, BAUMERT M, JAVORKA M: Baroreflex sensitivity is reduced in obese normotensive children and adolescents. Can J Physiol Pharmacol 87: 565-571, 2009.

PERSSON PB, DIRIENZO M, CASTIGLIONI P, CERUTTI C, PAGANI M, HONZIKOVA N, AKSELROD S, PARATI G: Time versus frequency domain techniques for assessing baroreflex sensitivity. J Hypertens 19: 1699-1705, 2001. 
PORTA A, FURLAN R, RIMOLDI O, PAGANI M, MALLIANI A, VAN DE BORNE P: Quantifying the strength of the linear causal coupling in closed loop interacting cardiovascular variability signals Biol Cybern 86: 241-251, 2002.

PORTA A, CATAI AM, TAKAHASHI ACM, MAGAGNIN V, BASSANI T, TOBALDINI E, VAN DE BORNE P, MONTANO N: Causal relationships between heart period and systolic arterial pressure during graded head-up tilt. Am J Physiol Regul Integr Comp Physiol 300: R378-R386, 2011.

PORTA A, BASSANI T, BARI V, PINNA GD, MAESTRI R, GUZZETTI S: Accounting for respiration is necessary to reliably infer granger causality from cardiovascular variability series. IEEE Trans Biomed Eng 59: 832-841, 2012.

ROBBE HWJ, MULDER LJM, RUDDEL H, LANGEWITZ WA, VELDMAN JBP, MULDER G: Assessment of baroreceptor reflex sensitivity by means of spectral-analysis. Hypertension 10: 538-543, 1987.

SVACINOVA J, HONZIKOVA N, KRTICKA A, TONHAJZEROVA I, JAVORKA K, JAVORKA M: Diagnostic significance of a mild decrease of baroreflex sensitivity with respect to heart rate in type 1 diabetes mellitus. Physiol Res 62: 605-613, 2013.

ZAVODNA E, HONZIKOVA N, HRSTKOVA H, NOVAKOVA Z, MOUDR J, JIRA M, FISER B: Can we detect the development of baroreflex sensitivity in humans between 11 and 20 years of age? Can J Physiol Pharmacol 84: 1275-1283, 2006. 